
\title{
3 Research Square \\ Factors Influencing Physicians' Departure from General Practitioners Field in Developing Countries: A Case Study in Iran
}

\section{Azad Shokri}

Social Determinants of Health Research Center,Kurdistan University of Medical Sciences, Sanandaj,Iran https://orcid.org/0000-0003-2976-4488

\section{Elmira Mirbahaeddin}

University of Ottawa

\section{Ali Akbari-Sari}

Tehran University of Medical Sciences

\section{Iraj Harirchi}

Tehran University of Medical Sciences

\section{Fereshteh Farzianpour}

Tehran University of Medical Sciences

Abbas Rahimi Foroushani

Tehran University of Medical Sciences

\section{Somaieh Shokri}

grash

\section{Sima Mirzaei Moghadam}

Kurdistan University of Medical Sciences

Mahboubeh Bayat ( $\sim$ h.bayat57@gmail.com )

Iran Ministry of Health and Medical Education

\section{Research}

Keywords: General Practitioners, physicians' departure, immigration, unemployment, non-medical Iran

Posted Date: July 17th, 2020

DOI: https://doi.org/10.21203/rs.3.rs-43663/v1

License: (c) (i) This work is licensed under a Creative Commons Attribution 4.0 International License.

Read Full License 


\section{Abstract}

Background: Migration, intersectoral flows, early retirement, illness and premature death of General Practitioners (GPs), maintaining adequate and effective workforce has become a major challenge in many countries. The present study aimed to investigate the factors affecting the departure of physicians from the GPs field in developing countries.

Methods: We used qualitative research and performed as a conventional content analysis through indepth interview. Sampling method was purposeful sampling which was performed with variation in individuals include policy makers and different situation in GPs (including immigration, unemployment, specialty student, employment in other non-medical jobs, etc.). Lincoln and Guba evaluation method were used to determine the validity and reliability of the study. The conceptual model was used to illustrate the situation and deeper understanding of the problem

Results: The results of the interviews showed, eight themes, 22 sub-themes were identified as factors influencing tendency GPs to other states. Major themes included income, referral system, specialization, human resource policy-making, education related issues, working environment conditions, quality of life and community attitude. The causal relationships were shown inside and outside each theme in the conceptual model.

Conclusion: According to the results, there are various factors that lead people out of the field of GP and their tendency to different states, while lack of awareness of policy makers and officials can make decisions for years to come. A wide range of interventions is recommended to reduce these stimuli include pre-selection reforms such as "information about physicians' working conditions", during academic training such as "changing hospital education to clinic education and rural community experience" and after entering areas of the medical profession such as "defining the career path for physicians 'distribution and physicians' career development" and long-term reforms include fundamental reforms to promote family medicine referral and change community attitudes.

\section{Background}

General practitioners (GPs) are one of the main providers of health care, thus, the status of this group of providers because of the nature of their work is very important. Nevertheless, due to migration, intersectoral flows, early retirement, illness and premature death, maintaining adequate and effective workforce has become a major challenge for many countries [1]. Some physicians emigrate from one country to another and leave their workplace entirely to join other countries. Other physicians leave their workplace temporarily due to illness or in order to attend advanced training courses. Finally, other remaining physicians are permanently lost because of death or employment in the non-health care sectors [2, 3]. Unfavorable working conditions, remuneration and opportunities for poor career development opportunities and other labor market pressures so-called as "push" and "pull" factors affect physicians' performance status and may encourage them to leave work $[2,4]$. This situation in turn will 
have negative impacts on team productivity, disrupts organizational performance, and leads to loss of organizational memory which, in turn, increases the cost of health care and reduces the quality of services [3-5]. So being aware of these issues can have a considerable impact on the future policies of countries [6]. For example, studies indicated that if a region faces a high rate of manpower outflows, the input rate should increase more rapidly. Countries that suffer from HIV / AIDS deaths or have higher levels of cross-country migration, their active manpower are facing greater pressure. In some countries, their health system relies on external human resources flows or other countries face the challenge of leaving internal healthcare professionals $[4,7]$.

Overall, although studies on GPs force flows are limited, it should be noted that the identification of manpower flows alone is not sufficient and requires to analysis the cause of these flows at various levels. For example, countries which experiencing large inflows must understand why they rely on international labor. Whether the domestic production of manpower in the country is inadequate, or the unequal geographical distribution or present problems in maintaining domestic labor have been such that external inflows have replaced domestic outflows. Countries that are experiencing large outflows should understand whether these outflows are result from over-production of physicians in the health care sector or caused by inability to meet the costs of using these forces, or because of poor or worsening working and living conditions that has led to the flow of power to other sectors and migration to other countries. In fact, flows of medical personnel in the health care sector are associated with deeper resources and purposes problems of the health system $[8,9]$. Ignoring these movements will only delay the main issue. Therefore, the present study aimed to investigate the factors affecting the departure of physicians from the GPs field in Iran as a representative of developing countries.

\section{Methods}

The present study is a qualitative research and performed as a conventional content analysis in 2020 . In this approach, direct information from the study is obtained without imposing predetermined categories or theories. The research population included physicians and other GP graduates and decision makers and policy makers involved in the field of human resources and health policy making in the Ministry of Health and universities. Sampling method in this phase of the study was purposeful sampling which was performed with variation in individuals up to saturation level.

Considering that in the qualitative approach the phenomena should be studied in the natural context, different situation in GPs (including immigration, unemployment, specialty student, employment in other non-medical jobs, etc.) were regarded as sampling classes. Also, to complete the considered sample, experts who were in different fields and involved with different types of physicians were recruited. For example, managers who working in foreign graduates' sector were used to analyze physicians' migration information.

In order to collect data, in-depth interview based on interview guide was used. After determining the purpose of the interview, the list and characteristics of the interviewees, including medical graduates with 
different modes and HR experts working in different sectors, were determined. Then, based on the interviewee's status, general questions related to the different factors affecting each category were defined and in-depth interviews were conducted with the interviewee by appointment. All interviews were recorded and written word by word immediately. In order to extract the codes, constant comparison approach and inductive analysis approach were used. In other words, the words, sentences, and paragraphs of the participants' statements that contained important and relevant points of the research topic were considered as semantic units annotation at the margin of the text along with the encoding was done. For primary coding, participants 'own words were used and adjusted based on the researchers' perceptions of their words. The codes were re-read several times to assigned thematically under the subthemes and themes.

It should be noted that at this stage the codes were limited by similarity, and were categorized based on semantic and conceptual differences. In the next step, definitions were provided for each theme, sub theme and code and so, the factors affecting each case were discussed. Saturation was obtained when the previous data were replicated and sampling was completed.

In this study, Lincoln and Guba evaluation method were used to determine the validity and reliability of the study. For this purpose and based on this method, four criteria including credibility, dependability, confirmability and transferability was considered for evaluation [10]. To achieve credibility, the researcher increased the credibility of the research data to an acceptable level by spending enough time, interacting with participants, and verifying information from participants. Repeated step-by-step data collection and analysis, and review by supervisors, consultants, and experts were applied to enhance the data reliability. In order to increase the data confirmability criterion, experts' approval in the field of qualitative research and their complementary comments were applied. Some extracted elements were consulted with a number of experts who were not involved in the research to ensure the transferability of the research as well as to provide a rich description of the research report. Finally, key categories of concepts expressed by the participants were identified and their relationship to the main themes and other categories assigned and by engaging the participants and using their own attitude, the relationships between the categories were determined and to illustrate the situation and deeper understanding of the problem, a conceptual model was used.

\section{Results}

Overall, 11 medical graduations were interviewed who were engaged in other fields either medical or nonmedical fields, or those who experienced one of them. In addition, seven experts of MOHME who were definitely involved in GPs fields were interviewed. The majority of the participants were male (14 subjects) and (were) less than 45 years old (Table 1). Finally, 8 themes, 22 sub themes were identified as factors influencing tendency GPs to other states (Table 2). Also, the number of references to each code is indicated in the table. 
Table 1

Characteristics of participant sample

Characteristics

$n=18$

I. Organization Position of Experts and their Majors

Chief executive

Healthcare management

1

Specialist physician

2

Department head

Healthcare management

Management 1

GP

1

Epidemiologist

1

II. The current situation of physicians

Medical specialist / Residency

2

Health related employment

4

Leave the physician profession (Non-health employment) 1

Unemployment / Return from immigration

GP

Sex

Male

Female

Age

$45-55$ 
Table 2

Main factors affecting specialists' tendency towards DP

\begin{tabular}{ll} 
Theme & Subtheme \\
\hline A. Income & A1: The income gap \\
& \\
& $\begin{array}{l}\text { A2: Income generating } \\
\text { job opportunities }\end{array}$
\end{tabular}

Issue

A1-1 mismatch between billing tariff rates with the GPS work value

A1-2 income difference of GPS

A1-2-1 the income difference of specialist physicians and non-medical occupations with GPS

A1-2-2 the income difference of the physicians in Iran with the other countries

A2-1 the growing demand of the market for some services like beauty services and other cosmetics related businesses

A2-2 opportunities to make money in the other countries

B. Referral system

C.

Specialization
B1: The position of GPs in health/ referral system
B1-1 lack of a definite position in the health/ referral system for GPs

B1-2 overlap between GPs roles with specialist physicians

B2: Referral noncompliance
B2-1 insufficient knowledge about the referral system special in rural areas

B2-2 the authorities are not sure about the referral system
C1: Advantages of specialization in medical
C1-1 advantages of job

C1-1-1 advantage of the faculty in universities

C1-1-2 advantage of ecruitment in in public centers and universities

C1-1-3 advantage of work in metropolitan areas

\section{C1-3 high position gain in the community}

C2: Willingness to specialize
C2-1 tendency toward specialization in all fields in Iran

C2-2 tendency of community toward specialization
D. Human resource policy-making
D1: Unrealistic approach in the formulation of human resource policies
D1-1 decision-making without knowing enough about the health market

D1-2 policies making are subject to conditions, not based on need

D2-1 lack of a plan for employing GPS
D2: Lack of Career Development Policies 


\begin{tabular}{|c|c|c|}
\hline Theme & Subtheme & Issue \\
\hline & & $\begin{array}{l}\text { D2-2 lock of change in the GPs status after years of work } \\
\text { in the hospital }\end{array}$ \\
\hline & & D2-3 Lack of job development paths for GPs \\
\hline & & D2-4 the uncertain future of GPs in Iran \\
\hline & \multirow[t]{3}{*}{$\begin{array}{l}\text { D3: Wrong Student } \\
\text { Admission Policies }\end{array}$} & $\begin{array}{l}\text { D3-1 increasing physicians admittion in universities } \\
\text { aimed at responding to community health needs }\end{array}$ \\
\hline & & D3-2 increasing physician aimed at mass satisfaction \\
\hline & & $\begin{array}{l}\text { D3-3 increasing physician aimed at improving } \\
\text { physicians' istribution status }\end{array}$ \\
\hline & \multirow{2}{*}{$\begin{array}{l}\text { D4: Lack of } \\
\text { Appropriate Approach } \\
\text { to Human Resource } \\
\text { Distribution }\end{array}$} & D4-1 Lack of a detailed plan for the distribution of GPs \\
\hline & & $\begin{array}{l}\text { D4-2 non-motivational approaches to physicians' } \\
\text { turnover in the regions }\end{array}$ \\
\hline \multirow{10}{*}{$\begin{array}{l}\text { E. Education } \\
\text { Related } \\
\text { Issues }\end{array}$} & \multirow{6}{*}{$\begin{array}{l}\text { E1: Content and poor } \\
\text { implementation of the } \\
\text { curriculum }\end{array}$} & E1-1 Poor education program \\
\hline & & $\begin{array}{l}\text { E1-1-1 university education does not meet the needs } \\
\text { of society }\end{array}$ \\
\hline & & $\begin{array}{l}\text { E1-1-2 the difference between the nature of GP and } \\
\text { educational content }\end{array}$ \\
\hline & & $\begin{array}{l}\text { E1-1-3 some disregarded common diseases in Iran in } \\
\text { medical courses }\end{array}$ \\
\hline & & $\begin{array}{l}\text { E1-1-3 the shadow of moving towards specialization } \\
\text { in medical education stages }\end{array}$ \\
\hline & & $\begin{array}{l}\text { E1-2 Lack of educational space for GPs in mother } \\
\text { universities }\end{array}$ \\
\hline & \multirow[t]{4}{*}{$\begin{array}{l}\text { E2: Unrealistic } \\
\text { Approach to Choosing } \\
\text { the medical majors }\end{array}$} & $\begin{array}{l}\text { E2-1 Students choose medicine major based on social } \\
\text { prestige and financial gain in university national entrance } \\
\text { exam in Iran (Konkoor) with no interest or knowledge }\end{array}$ \\
\hline & & $\begin{array}{l}\text { E2-2 Students choose medicine major based on rank in } \\
\text { university national entrance exam in Iran (Konkoor) with } \\
\text { no interest or knowledge }\end{array}$ \\
\hline & & $\begin{array}{l}\text { E2-3 Choosing the medical major due to family pressure } \\
\text { with no interest or knowledge }\end{array}$ \\
\hline & & $\begin{array}{l}\text { E2-4 the lack of awareness of students and families } \\
\text { about the working conditions of physicians }\end{array}$ \\
\hline \multirow{2}{*}{$\begin{array}{l}\text { F. Working } \\
\text { environment } \\
\text { conditions }\end{array}$} & \multirow{2}{*}{$\begin{array}{l}\text { F1: Inappropriate } \\
\text { working environment }\end{array}$} & F1-1 stress and workload of GPs \\
\hline & & $\begin{array}{l}\text { F1-2 fear of being separated from the family because of } \\
\text { frequent night shifts }\end{array}$ \\
\hline
\end{tabular}




\begin{tabular}{|c|c|c|}
\hline Theme & Subtheme & Issue \\
\hline & \multirow[t]{2}{*}{$\begin{array}{l}\text { F2: Lack of Job } \\
\text { Security }\end{array}$} & $\begin{array}{l}\text { F2-1 limited job opportunities result in inappropriate } \\
\text { distribution of GPS and over-saturation of doctors in } \\
\text { urban areas }\end{array}$ \\
\hline & & $\begin{array}{l}\text { F2-2 lack of job opportunities after mandatory national } \\
\text { service }\end{array}$ \\
\hline & \multirow{3}{*}{$\begin{array}{l}\text { F3: Attitude toward } \\
\text { unethical issues in the } \\
\text { workplace }\end{array}$} & $\begin{array}{l}\text { F3-1 requests for immoral / legal activities during } \\
\text { medical practice behalf of hospital }\end{array}$ \\
\hline & & $\begin{array}{l}\text { F3-2 tendency for immoral / legal activities to increase } \\
\text { their income }\end{array}$ \\
\hline & & F3-3 commercialization of medical in Iran \\
\hline & \multirow{3}{*}{$\begin{array}{l}\text { F4: Poor living } \\
\text { conditions during } \\
\text { compulsory plan }\end{array}$} & F4-1 lack of amenities in rural areas for their families \\
\hline & & $\begin{array}{l}\text { F4-2 distance the continuation of the educational and } \\
\text { career development of physicians }\end{array}$ \\
\hline & & F4-3 difficult living conditions in the village for GPS \\
\hline \multirow[t]{5}{*}{$\begin{array}{l}\text { G. Quality of } \\
\text { life }\end{array}$} & \multirow[t]{2}{*}{$\begin{array}{l}\text { G1: Achieving a Better } \\
\text { Life }\end{array}$} & $\begin{array}{l}\text { G1-1 poor living conditions in Iran, due to security, } \\
\text { pollution, traffic, cultural problems, etc. }\end{array}$ \\
\hline & & G1-3 the decline in married opportunities for women \\
\hline & \multirow[t]{3}{*}{ G2: Couple Problems } & $\begin{array}{l}\text { G2-1 left the country because of family working } \\
\text { conditions }\end{array}$ \\
\hline & & $\begin{array}{l}\text { G2-2 excluded from the medical field due to adherence to } \\
\text { their spouse's job }\end{array}$ \\
\hline & & G2-3 addressed the female physicians' safety concerns \\
\hline \multirow{7}{*}{$\begin{array}{l}\text { H. } \\
\text { Community } \\
\text { attitude }\end{array}$} & \multirow{3}{*}{$\begin{array}{l}\text { H1: Misconceptions } \\
\text { about the medical } \\
\text { profession }\end{array}$} & $\begin{array}{l}\text { H1-1 the definition of community of a physician as who } \\
\text { specialize }\end{array}$ \\
\hline & & $\begin{array}{l}\text { H1-2 comparing GPs with specialist physicians by } \\
\text { community }\end{array}$ \\
\hline & & $\begin{array}{l}\text { H1-3 the definition of community of GPs as responsible } \\
\text { for referral to high levels }\end{array}$ \\
\hline & \multirow{2}{*}{$\begin{array}{l}\text { H2: False Expectations } \\
\text { before Entering } \\
\text { Medicine }\end{array}$} & H2-1 Expect to achieve the best financial situation \\
\hline & & H2-2 Expect to get the best social status \\
\hline & \multirow{2}{*}{$\begin{array}{l}\text { H3: The reduction of } \\
\text { the interest of society } \\
\text { to GPs }\end{array}$} & H3-1 reduce the public's interest in visiting a GP \\
\hline & & H3-2 interested in receiving services from specialist levels \\
\hline
\end{tabular}

\section{A. Income}


Income was one of the principal factors affecting the shift towards other occupations which may be similar or may not be similar to their old status. The income gap was organized into two subthemes including the gap between GPs and the other professions, and Income generating job opportunities.

A1. The income gap: In recent years, income difference between specialist physicians and GPs has always been one of the challenging issues in Iran's health system. Some believe that this difference led to an increased tendency towards specialty state: "the difference income of specialist physicians with GPS is high, even in comparison with surgeon areas really is very high" (P6), physician. Regarding mismatch between billing tariff rates with the GPs work value, subject matter experts stated that "although specialists' tariff were modified, we were not able to correct it in the field of GP. For example, when a GP refers a patient to a cardiologist, the share of a GP is only a visit which worth's $1 \$$, while a specialist receives more than 1,000\$ only for an angiography" (P16), expert. Also, regarding the income gap between GPs and non-medical occupations/health professionals in mental healthcare some physicians mentioned that "my friends own the store or they work in construction. They own Toyotas worth 15,000\$ and I can afford only 4,000\$ to get a car, considering years of savings that I reserved for this" (P3), physician. One of the experts compared the income difference of the physicians in Iran with the other countries and said that "we can't pay salaries and benefits like the United States, because of our financial limitations. Australia is one of the countries that provide high income for the GPs as a strategy to attract doctors from other countries"(P15), expert.

A2. Income generating job opportunities: Existence of high income-generating opportunities has driven GPs to seek the other opportunities for higher income (such as real estate investments, construction, beauty services and etc.). Some interviewees referred to the growing demand of the market for some services like beauty services and other cosmetics related businesses. "The demand for beauty services is growing increasingly. Therefore, when demand for a service is higher, physicians' tendency to offer these types of services will increase" (P6), physician. "There are some jobs with less effort to make loads of money. I spent more than 20 years of my life working at a rural area and now I'm receiving only $400 \$$ " (P15), a physician said. Some physicians raised the conversation about the current opportunities to make money in the other countries and why the GPs immigrate to high-income countries: "physicians attain higher income abroad than in Iran. Even the physicians who received scholarship supports and education grants didn't return, despite losing the collateral that they left at the country (Iran) worth of more than $30000 \$$ as a promise to return to Iran's health system. They received the scholarship from MOHME to study (in Emergency Medicine at one of the USA universities), but they never returned and made enough income in less than a year that compensated what they left behind in the country"(P12), expert.

\section{B. Referral system}

In countries with a referral system, a family physician is a gatekeeper to manage a patient's treatment. In a gatekeeper system, family physicians decide whether or not medical specialist care is needed. The 
referral system challenge was identified in two sub-themes: The position of GPs in health/ referral system and Referral non-compliance.

B1. The position of GPs in health/ referral system: Some interviewees believe that GPs don't have the defined position in the health system, despite their effective roles. It seems that it led to an increased tendency towards specialty state or other professions: "in most developed countries the position of GP defined and has been placed on the first line of treatment. When a patient needs to be referred to a specialist, the patient contacts with the gatekeeper, and he/she decides whether or not medical specialist care is needed. But in Iran, you can't see a definite position for GPs especially in the referral system" (P3), physician. One of the experts paid to overlap between GPs roles with specialist physicians due to lack of a definite position in the health system for GPs: "the specialists provide the services for patients who need to GPs services. Because the income of specialists depends on the number of visits. Therefore, without a definite position, even patients who have colds are visited by specialist physicians"( $P 17)$, expert.

B2. Referral non-compliance: Based on the statement of the participants, insufficient knowledge about the referral system is the most important problem in an increased tendency towards other professions. A physician mentioned that "the majority of patient requests are for specialty care. Base on the villager's view, GPs have less understanding of medical problems. Therefore, they refer to specialists" (P5), physician. "About $50 \%$ of people refer to specialists in the first visit while they have no knowledge of disease and specialty" (P6), expert. Also, an expert stated that the authorities are not sure about the referral system: "even we are not sure about the gatekeeper role of GPs. We don't know how to make sure that the patient is guided and visited properly. They were not trained well enough to lead patients. We only paid attention to the quantity of GPs. After the revolution in 1979, we used to Indian and Pakistani physicians and at that time we had to increase medical student admissions to meet medical needs. So, the educational quality was ignored in medical schools" (P16), expert.

\section{Specialization}

In these days, when there is a tendency to specialize in all fields, among GPs has reached its peak. Therefore, Specialization is an important factor in the tendency of GPs towards specialty due to its advantages.

C1. Advantages of specialization in medical: Based on the statement of the participants, advantages of specialist physicians compared to GPs including higher income, more support of insurance organizations, advantages of the faculty and other advantages were factors which led to a tendency of GPs towards specialty. A physician mentioned that "most of GPs take part in residency examination only due to the advantage of faculty" (P5), physician. "GPs in public centers and universities are recruited much less than specialist physicians. Often universities allocated employment opportunities to attract specialist physicians. That means the only way for GPs to take part in one of the specialist areas"(P6), physician. Other physicians mentioned that "you make this possible for yourself to continue work in 
metropolitan areas or even in private clinics, only you need to specialty certification"( $P 9)$, physician. A neurosurgeon mentioned that a high position in the community is gained by inter to one of the specialist areas: "the GPS position was a low-level position for me but now l've got much more than the something that I thought. I never got this feeling when I was GPs"(P7), physician.

C2. Willingness to specialize: It seems that in democratic societies tend to specialty be common among GPs due to the importance of meet community priorities and demands people. A physician stated: "the society willing to specialize and they don't value GPs"(P5), physician. Most of the participations agreed that the trend of specialization among all fields in Iran is the main factor in the tendency of GPs to specialty. "The tendency toward specialization is a natural thing. So, all areas are going to specialize" (P14), expert. "In Iran, GPs got to specialty if they were able. Unfortunately, each of GPs is trying to continue in a special field. Although most of them have a good income, they toward this position due to the trend of community to specialization" (P13), expert.

\section{Human resource policy-making}

In recent years, the issue of policy-making in the health sector is one of the major topics. Failure to formulate appropriate policies will lead to unfavorable results. Therefore, human resource policy-making was an issue that effects on GPs.

D1. Unrealistic approach in the formulation of human resource policies: Studies and other evidence help policy-makers in their decision-making and also the best evidence is used to establishment,

implementation, and development of policies. However, in Iran decision-making isn't evidence-based: "the lack of knowledge about the GPs condition is one of the main obstacles which lead to wrong decision making. Policymakers must be informed of the healthcare market and target group status to formulate the appropriate policies" (P18), expert. One expert argued that health system policies are subject to conditions and not based on need: "In Iran, policies are subject to conditions, while conditions must be subject to policies. For example, the reason that the health system introduces a family physician specialist is to keep people happy, Why do we want a family physician specialist at all, just a GP is enough?(P14), Expert.

D2. Lack of Career Development Policies: Experts believe the health system should provide the fields of work for number of physicians that admit in universities: "There is no strategy in Iran for employing labor. It means a fully education-based system that only teaches people with no plans to use them. "P(17), Expert." We distribute medical graduates to remote areas for commitment, but we have no plans to complete them. One time I was in one of the zero-border areas, a GP asked me, do you expect me to stay here for a few years? Should I stay a year or two more or 5 years? I have to stay here for a few more years. We had nothing to say."(P14), Expert. Some predicted the uncertain future of GPs in Iran as one of the main causes of exit: "Many of my peers have migrated to European and American countries because of no clear future in Iran." (P9), physician. They no longer believed there was any path forward for GPs: "After entering the hospital field, I realized that, unlike other jobs, after a few years of work, there would be 
no change in the GP status of the hospital. For example, every 10 years. Added to people's work experience, midwives and nurses worked less, but GPs were instructed. National was not defined" (P16), expert.

D3. Wrong Student Admission Policies: Admitting physicians to universities regardless of their postgraduation job status was solely aimed at responding to community health needs, including wrong policies affecting their orientation in previous years. One interviewee stated that "they have increased their admission to universities at some point in time. However, they had no policy of applying them after graduation. The aim was only to replace Iranian doctors with Indian and Pakistani doctors."(P4), Physician. Some believe that increasing physician acceptance is aimed at mass satisfaction: "Policymakers aim at increasing the number of physicians at mass satisfaction. Increasing physician treatment improves patients '(P7), Physician. Some believe that increasing physician acceptance is aimed at improving physicians' distribution status: "Decision makers increase capacity to complete service coverage, but capacity building cannot force physicians to serve in deprived areas, so doctors in urban areas are working" (P18), expert.

D4. Lack of Appropriate Approach to Human Resource Distribution: Inadequate physician distribution will increase physicians in metropolitan areas and reduce job opportunities and their inclination to other jobs for better income. "This is why the density of doctors in metropolitan areas is so high and ultimately lack of access to sufficient income makes many physicians turn to beauty services" (P7), Physician. Some non-motivational approaches to physicians' turnover in the regions of the country attribute the tendency of physicians to other areas. "There was no difference between physicians who served in metropolitan areas and those in remote provinces, and in most cases people in the better areas had more power to obtain office licenses" (P16), expert.

\section{E. Education Related Issues}

The issue of medical education and training of efficient human resources has always been the focus of educational planners. Medical colleges are responsible for the training of physicians who, while attentive, must be able to understand the needs of the community and have the necessary competencies for care.

E1. Content and poor implementation of the curriculum: A look at the developments in the country's higher education system over the past two decades shows that these developments have had little approach and the quality of university education has not been adequately addressed. From the perspective of interviewees, university education does not meet the needs of society: "Education in our country is not at all commensurate with market needs. (P6), Physician. "That is, when you are educated, it is not something that is needed by the community" (P10), Physician. Some university education practitioners believe that the role and nature of the GPs is different: "In universities, no one attends public education. All academic courses are related to specialized medical courses. However, the training must be comprehensive and provide us with a holistic view of our GPs or family physician" (P1), Physician. "GPs receive treatment-based training. Total health education and preventive measures out of a total of 7 years 
of medicine are 1 month. While expecting a GP in the treatment team is not a cure, it is a cure for health" (P7), Physician. Some disregarded common diseases in Iran in medical courses: "GP science is more of an ecological science and a regional science, while our resources relate to other countries and their diseases" (P9), Physician. "We are sorely lacking about the epidemiology of common diseases in Iran." (P2), Physician.

According to one of the experts, one of the main factors of GPs' tendency to specialize is the shadow of moving towards specialization in medical education stages: "At all stages of education physicians can move towards becoming specialist. Many of the lessons are part of what one would never expect from a GP and is about expertise" (P16), expert. According to one of the experts of all educational capacities in the mother universities is allocated to the assistant students: "Seeing patients is a priority for residents and above, so there is no time for a GP to have a history and examination" (P16), expert.

E2. Unrealistic Approach to Choosing the Major. Choosing the university major with no interest or knowledge usually leads to a change of field and a tendency for other jobs. Many people enter medical careers for social and credit related reasons and for financial gain because of their lack of interest in moving to non-medical careers: "I was one of those who chose medicine with my own interests. I haven't. I chose this field because it is socially good and luxury. In fact there was no initial interest" (P3), Physician. Some have cited family pressure to pursue medicine as a challenge for physicians to pursue other jobs: "In Iran, some are entering the field because of family pressure that their children expect." (P13), expert. "One of my friends had no interest in medicine at all. He only studied medicine in Russia under his father's compulsion and therefore entered the IT field" (P17), expert. According to one of the physicians in Iran, the field of study is based on the university entrance exam and many people are just because of the high medical degree: "The top must go into medical fields" (P11), Physician. From the interviewees' point of view, the lack of awareness of students and families about the working conditions of physicians would lead to a tendency for non-medical fields: "When I entered the field, I realized that this field was incompatible with my spirit" (P12), Physician. "By the time I got into management, I was in better shape and in tune with my mood"(P11), Physician. So they decide to change their discipline.

\section{F. Working environment conditions}

A work environment is a social and psychological environment characterized by a range of physical factors, organizational policies, and behavioral traits of the individuals in whom they work. The work environment is an important topic that has been addressed.

F1. Inappropriate working environment: Inappropriate working conditions affect not only performance but also dissatisfaction and stress. Overnight shifts can disrupt people's biological clock, which results in fatigue, tiredness, insomnia, anorexia, lack of concentration and memory loss. One doctor commented on night shifts and the fear of being separated from the family because of frequent night shifts that "night shifts bothers people and keeps them away from the family. I'm married now but I'm not at night most of the time and I'm shifting" (P1), Physician. "Sometimes it is difficult to tolerate pain and high volume of 
patient visits. The overwhelming number of patients and ongoing stresses have a negative impact on one's psyche. In order to escape this workload, I tried to work on other side-by-side disciplines besides practicing medicine" (P2), Physician.

F2. Lack of Job Security: GPs do not find suitable job opportunities after graduation when they enter the job market and are forced to meet their basic needs in order not to be shaken by the economic life cycle. Other businesses are turning. One of the physicians in support of the issue stated, "There are no job opportunities for these village family doctors now when their mandatory national service is finished and they enter the job market. If you are going to provide services in the office, it would actually be useless because they would have a limited number of clients. "(P6), Physician. "I had a particular interest in bedding and I loved medicine. But in Tehran it was not a metropolis, so then I had to either work in cities or in the surrounding villages" (P5), Physician.

F3. Attitude toward unethical issues in the workplace: Disseminating immoral behaviors, especially in individuals and groups that must be trusted and trusted by the public, undermines public trust and exposes them to the public. In the medical community, ethics is of particular importance because of the importance of the medical profession. Some interviewees cited the commercialization of medical in Iran and the changing nature of the relationship between physician and patient: "medical has become commercially viable and has lost its place and money has taken its place from health to health business" (P17), Physician. "In Tehran and other metropolitan areas, due to the high density of doctors and the diminished number of referrals, they resort to unethical issues such as induction demand, sometimes being treated ill without the need for treatment." (P8), Physician.

One physician who described the experience of dealing with immoral demands as a reason for not continuing to work in the medical field explicitly addressed requests for immoral / legal activities during medical practice: "I was in the clinic for three nights. On the first night I was asked for a medical certificate without seeing the patient, the next night an old man was sleeping and I was asked to issue a death certificate, while it was required by law to stay in the hospital for at least 72 hours to get a certificate. The third night I was wondering why I didn't prescribe extra serum for my patients. The pharmacy and clinic will be broken. I've seen these scenes where you have to either go to market or abandon medicine altogether. "(P7), Physician.

F4. Poor living conditions during compulsory plan: Compulsory Medical and Paramedical Service Plans in spite of the undeniable achievements that have been made in improving access to medical services in deprived areas, the medical community has repeatedly criticized or protested. Failure to resolve the living problems of doctors in rural areas has reduced the incentive to serve in deprived and border areas. Some doctors pointed to the difficult living conditions in the village

"I would put water bowls under the base of the bed so that the scorpion would not rise from the bed. Or I would go on tour. "These conditions lead either to doctors seeking a specialty or to pursuing a career in the profession and to pursue other non-medical care" (P6), Physician Some pointed to the lack of amenities in rural areas for their families: "If we work in the worst-case scenario, there is a discussion with 
other family members, my child cannot study in a good school, my wife cannot a place to live with decent facilities" (P10), Physician. According to one physician, Compulsory service will distance the continuation of the educational and career development of physicians: For this reason many of my peers immediately went into specialization to escape forced labor and living in remote rural areas." (P7), Physician.

\section{G. Quality of life}

People in different countries, although economically prosperous, migrate to improve their quality of life if they feel that their lives are not of good quality. This section will discuss issues related to quality of life and its impact on physician migration.

G1. Achieving a Better Life: According to the majority of interviewees, poor living conditions in Iran, due to security, pollution, traffic, cultural problems, etc., have caused physicians to migrate to other countries for better living conditions. "Many physicians are migrating to developed countries in order to achieve a better life,"said one foreign affairs official. Some were even willing to immigrate to other developed countries for senior public health. "We have professionals who make good money here, but because of better quality of life they have migrated to a number of countries, such as the United States, to European countries whose quality of life is better. "(P12), expert. "In Tehran, you are going to get out of the car. You will encounter car traffic, you will have a verbal fight during the day, you have air pollution. Do, compliment, smile" (P13), expert. One expert cited the decline in life opportunities for women: "After graduating, they cannot get married, they have grown old, and for women, employment is essentially the third and fourth priority. That's why it is easier for women to quit their jobs. "(P17), expert.

G2. Couple Problems: Each job has its own set of benefits, each with its own set of issues, and each one deals with these issues in some way, sometimes involving the unwanted or unwanted issues of the family. In the opinion of some women interviewees, women are excluded from the medical field due to adherence to their spouse's job: "When my husband was sent to another city to plan, I couldn't get out of town every day to get to work" (P7), Physician. "Some women have left the country because of their working conditions. These people were subject to the conditions and were not the decision makers. So they had to migrate because of their living conditions. "(P12), Physician. "I had to immigrate to Canada because of my wife's education" (P8), Physician.

Others addressed the female physicians' safety concerns: "It's a problem for women themselves. There are families whose lives have become difficult and that is why they have to choose one" (P12), physician. "On the nights when a lady doctor has to go to physician home in the village, she has to be very careful and try to keep herself safe" (P9), physician.

\section{H. Community attitude}


Undoubtedly, the influence of cultural factors on human behavior is certain, and cultural priorities are one of the causal components in the desires of a society. Thus the judgment of individuals on different groups, such as physicians, will inevitably be influenced by the culture of the society in which they are formed.

H1. Misconceptions about the medical profession: Attitudes in the community about physicians are an important factor in changing their behavior. Interviewees also believe that some attitudes, such as comparing GPs with specialist physicians, have caused frustration for physicians to work in the medical field. "The differences are not just four years of college, much more. The specialist physician is much better than the GP. For this reason, many GPs go into pediatric and infectious medicine disciplines that do not have the same income regardless of income." (P13), expert. Some physicians believe that the definition of community is that of a physician who specializes: "When someone asks me about my job and I answer that I am a physician, I am immediately asked what kind of expertise do you read? That is, the general public is not considered a doctor at all. "(P3), Physician.

Some believe that people's perception of the GP is solely responsible for referral to high levels, not the person responsible for the care and treatment of the community: "People think the GP is responsible for referring them to specialists and higher levels than they are, so they only expect referral to the specialist when they go to the GP" (P6) Physician.

H2. False Expectations before Entering Medicine: The dignity and status of some disciplines in society is the main cause of volunteers' tendency to study in these disciplines. The astronomical income of physicians and the publication of news in this regard have made the students much more interested in studying medicine. "Some people think that by becoming a doctor they can make money early or get to social status, but they find that this is not the case, and because they have not chosen this field, they are looking for their interests in There will be other fields" (P14), expert. "People go into medicine to get the best social status because they don't think they are looking for the expertise to get to the position they were expecting" (P11), Physician. "As she enters the hospital, she understands the medical difficulties. On the one hand, he does not see much shifts and waking nights, and on the other he does not see the respect he intended" (P7), Physician.

H3. The reduction of the interest of society to GPs: Today, the number of GP visits has decreased and people are less likely to go to the GP. According to experts, one of the main reasons for the tendency of physicians to specialize is to reduce the public's interest in visiting a GP. One doctor said: "Not many people pay the GP"(P5), Physician. "People are not interested in being seen by a GP, even if someone has a cold"(P9), Physician. "Some friends who have an office can barely afford the office. So they tend to move to other fields such as homeopathy, beauty, traditional medicine, etc. (P10), Physician.

According to some interviewees, people are interested in receiving services from specialist levels: "Most people after the disease are interested in seeing their specialist, not the GP" (P1), Physician. "Even many people are willing to spend a great deal of time and money treating their specialist doctor without having 
to see a specialist" (P4), Physician. Therefore, these attitudes in the community will cause physicians to frustrate their activity in the field or their tendency to specialize.

\section{Conceptual Framework of causal relationships}

Figure 1 presents the themes and subthemes in a concept map, which were subdivided into general categories during the analysis. As can be seen, causal relationships were shown inside and outside each theme.

As can be seen, "job security" is affected by factors related to human resource policy, including the lack of an unrealistic approach to human resource policy formulation, the correct approach to the distribution and organization of human resources, the lack of job development policies, and so on. GPs are in the health / referral system. Under the theme of "desire to specialize", they are not only influenced by the benefits of medical expertise but also by the public's perception of the medical profession and the decline of community interest in GPs and the weakness of educational programs. There is a lack of career development policies for GPs.

It is also observed that the weakness of educational programs and the prevalence of unethical issues in the workplace have diminished the public interest in GPs. Expectations before entering medicine will lead to an unrealistic approach to discipline among students and medical discipline, and ultimately, the income gap will affect access to a better quality of life and lead physicians to immoral issues at home. It's been done. Details of other causal relationships are given in Fig. 1.

\section{Discussion}

Based on the results, 8 factors influencing the activity of GPs were identified. Among developed countries $[11,12]$ and developing countries $[13,14]$ wage and quality of life factors were the most important factors affecting their status and career path, followed by working conditions and human resources policies. In a systematic review, low incomes were identified as one of the factors influencing physicians' exit [15]. In China, income had a direct influence on the career choice of medical students [16]. In a survey of physicians in Lithuania, Hungary, Poland, Romania and Slovakia, as well as in Germany and Turkey, income played a decisive role in the career path of physicians and they had to leave the country and move to other countries for better income or better earning opportunities [17]. Even under the conceptual model, this would even prevent them from achieving quality of life and promoting immoral issues in the country. One of the WHO's strategies to increase the viability of physicians in developing countries has been the use of ethical issues in the workplace. Some countries such as Uganda [18] and Turkey [19] were used financial incentives to keep their doctors and reduce follows. However, most studies have concluded that rising incomes alone will not be effective.

Concerning the quality of life, some physicians believe that access to better quality of life is a priority for some physicians in Vanasse's study [20] and Costigliola's dissatisfaction with quality of life and lifestyle 
changes as a major contributor to family physician migration. Other countries cited. In the UK, improved quality of life as a major driver for migration to other countries [21]. Adherence to a spouse's job will cause them to quit or change jobs or take care of themselves. Children leave work because women play an important role in their upbringing. Nightmares have negative consequences on family matters and cause disruption of shared social activities with the spouse [22, 23]. Therefore, part of the WHO's strategies for improving living conditions, including environmental improvement, schools for children, is observed. Even the focus was on creating job opportunities for the spouse [13]. Even some strategies focused on flexible working hours and psychological interventions to reduce psychological stress to improve quality of life and maintain work force. Concerning workplace conditions, studies show that work stress and work stress have a direct effect on physicians' inactivity [24-26]. In the Maier study, high workloads caused migration or leaving the health sector [17]. Another study stated that if GPs had the impression that their workload would not change in the future, the likelihood of survival would be significantly reduced [27]. The likelihood of leaving physicians in remote centers and semi-skilled areas was 2.65 times and 1.33 times higher than those in semi-poor areas, respectively [28]. Opportunities for growth, better education for children, and so on, are preferred to their future careers, making rural areas an obstacle Capacity will be [29].

Other environmental factors include the lack of job security that this segment of society is facing. In the 1990s, the lack of job security and temporary contracts by Spanish health professionals led them to tend to Portugal, France and the United Kingdom [17]. According to the conceptual model of occupational safety, due to the lack of a clear position for GPs in the health system. For this reason, permanent recruitment strategies for physicians are used [27].

Concerning the issue of human resource policy among European countries, the impact of health care policy on the uncertainty of the development of the workforce was stated as one of the main factors in the exit of the health workforce [30]. In Chen 's study, lack of job development programs led to physicians leaving the country [31]. In Alameddine' s study, the lack of job development programs and job stability in the UK caused physicians to leave the countryside and confuse them. The concept of a lack of job development policies reduces job security and attracts doctors to specialization. Increasing student capacities has taken place in Turkey due to the lack of collective satisfaction in other countries as well. The number of physicians has had only a very small effect on distribution [32]. 980 to 1990 in Japan could not solve the problems of physician distribution [33]. The policies thus set out will be without regard to current needs and possible changes in the coming years [34], whilst policies without regard to its ultimate impact in some cases, regardless of its potential failure. Encountered and ultimately the health workforce involved in confusion and escaping problems.

Concerning the field of education, a study stated that training provided to GPs is often hospital-based and lacks outpatient and village-related training [13]. Another study shows that educational content does not meet community needs. (For this reason, many strategies are focused on modifying the content of medical education programs. For example, increasing clinical course programs in rural areas will familiarize students with rural issues.) 154. The Importance of Medical Students Understanding Rural 
Areas and Even Establishing Rural Schools in Countries in extended and developed has been done to confirm the effectiveness of this approach $[13,27,35]$. The conceptual model also observed that the weakness of educational programs would ultimately reduce the public interest in GPs. The unrealistic approach to discipline selection is also very common in Iran due to the specific conditions of its medical careers, its benefits, and its validity. The consequences of unrealistic selection of physicians' dissatisfaction in the future will be noted in some studies. It seems that dissatisfaction with the medical profession is due to the unrealistic approach in field selection due to the lack of knowledge of the actual situation of the students and the family.

Other factors discussed in this study include referral system, specialization and community attitudes. GPs do not have a specific position regarding the referral system in the structure of the Iranian health system and consequently face failure to follow the referral system, while at the international level between developed countries such as the US and European countries, the position of GPs It is clear and at the forefront of treatment. In Iran, family medicine performed well after several years of implementation, but the referral and referral system of specialist physicians and patient follow-up is not yet implemented correctly [36] in this study according to experts' conceptual model of misconception. Society regarding medical profession and unrealistic human resources policies have led to failure to implement the referral system which has also put doctors at risk for job security. According to conceptual model of weakness in medical education programs, society's misconception about medical profession and the advantages that specialist physicians have in creating the desire for expertise among GPs, It is worth noting that this issue is not limited to Iran alone. In Canada, studies show a strong desire to become a specialist in most countries, specialists are more valuable than GPs [37, 38]. In Turkey because of the desire for specialization among physicians, the path of family medical specialization to GPs has been established [19], which can expand their field in this way. Villagers of Iranian cities show family's awareness about poor family medicine program $[39,40]$. One study even stated that in the community's view, the value of family doctors' visits was cheap because of their low value for specialist physicians [41]. One of the main factors affecting their tendency to other situations has been.

\section{Conclusion}

According to the results of this study, there are various factors that lead people out of the field of GP and their tendency to different states. In general, these factors fall into three categories of factors related to health system policies in the country, community factors and individual factors, while lack of awareness of policy makers and officials can make decisions for years to come. Training GPs to provide the workforce in implementing various programs faces major challenges and drives them to leave GPs. Therefore, a wide range of interventions is recommended to reduce these stimuli. These short-term interventions should include pre-selection reforms such as "information about physicians' working conditions", during academic training such as "changing hospital education to clinic education and rural community experience" and after entering areas of the medical profession such as "defining the career path for physicians 'distribution and physicians' career development" and long-term reforms include fundamental reforms to promote family medicine referral and change community attitudes. 


\section{List Of Abbreviations}

Not applicable.

\section{Declarations}

\section{Ethics approval and consent to participate}

The ethical committee of Tehran University of Medical Sciences ethically assessed and approved the study methodology and ethical.

\section{Consent for publication}

Not applicable.

\section{Availability of data and material}

Data sharing is not applicable to this article as no datasets were generated or analysed during the current study.

\section{Competing interests}

The authors declare that they have no competing interests.

\section{Funding}

This study did not receive any kinds of funding resources.

\section{Authors' contributions}

AS and MB, contributed to study conception and AS, SS, EM, SM and IH gathered data design and all authors were involved in analysis and interpretation process of data. MB, AAS, AS and EM drafted and translated the manuscript and all the authors contributed by their comments of improvement in several revisions to reach a final manuscript.

\section{Acknowledgements}

We show appreciation to all people who assisted us to carry out this study especially MOHME Center for Health Human Resources Research and Studies (CHHRRS), MOHME human resource management office 
and Iran's Medical Council which facilitated the study. Also thanks to all participants that helped the data collection.

\section{References}

1. MacNeela P, Gibbons A, McGuire B, Murphy A: "We need to get you focused": General practitioners' representations of chronic low back pain patients. Qualitative Health Research 2010, 20:977-986.

2. Hagopian A, Thompson MJ, Fordyce M, Johnson KE, Hart LG: The migration of physicians from subSaharan Africa to the United States of America: measures of the African brain drain. Human resources for health 2004, 2:17.

3. Vujicic M, Zurn P, Diallo K, Adams O, Dal Poz MR: The role of wages in the migration of health care professionals from developing countries. Human resources for Health 2004, 2:3.

4. Organization WH: The world health report 2006: working together for health. World Health Organization; 2006.

5. Marmot M, Friel S, Bell R, Houweling TA, Taylor S, Health CoSDo: Closing the gap in a generation: health equity through action on the social determinants of health. The lancet 2008, 372:1661-1669.

6. Australia HW: Health Workforce Australia 2012: Health Workforce 2025-Medical Specialties-Volume 3. 2012.

7. Health CoSDo: Closing the gap in a generation: health equity through action on the social determinants of health: final report of the commission on social determinants of health. World Health Organization; 2008.

8. Dussault G, Buchan J: The economic crisis in the EU: impact on health workforce mobility. Health professional mobility in a changing Europe 2014:35.

9. Kinfu Y, Mercer HS, Dal Poz MR, Evans DB: Estimating inflows and outflows of health service providers in sub-Saharan Africa. Evidence and Information for Policy World Health Organization Geneva 2006.

10. Golafshani N: Understanding reliability and validity in qualitative research. The qualitative report 2003, 8:597-607.

11. Mistretta MJ: Differential Effects of Economic Factors on Specialist and Family Physician Distribution in Illinois: A County-Level Analysis. The Journal of Rural Health 2007, 23:215-221.

12. Salafsky B, Glasser M, Ha J: Addressing issues of maldistribution of health care workers. AnnalsAcademy Of Medicine Singapore 2005, 34:520.

13. Araujo E, Maeda A: How to recruit and retain health workers in rural and remote areas in developing countries: a guidance note. 2013.

14. Al-Shamsi M: Addressing the physicians' shortage in developing countries by accelerating and reforming the medical education: Is it possible? Journal of Advances in Medical Education \& Professionalism 2017, 5:210. 
15. Puertas EB, Arósquipa C, Gutiérrez D: Factors that influence a career choice in primary care among medical students from high-, middle, and low-income countries: a systematic review. Revista Panamericana de Salud Pública 2013, 34:351-358.

16. Mutha S, Takayama JI, O'Neil EH: Insights into medical students' career choices based on third-and fourth-year students' focus-group discussions. Academic Medicine 1997.

17. Maier CB, Glinos IA, Wismar M, Bremner J, Dussault G, Figueras J: Cross-country analysis of health professional mobility in Europe: the results. Health professional mobility and health systems Evidence from 2011, 17:23-66.

18. Ramadhan $\mathrm{H}$ : Retention challenges of human resources for health: what are the alternatives incentives for retention of skilled health workers in Uganda health sector? Medical Practice and Reviews 2015, 6:16-23.

19. Mollahaliloðlu S, Aydogan Ü, Kosdak M, Öncül HG, Dilmen U: Physician scarcity in underdeveloped areas of Turkey: what do new graduate physicians think? 2012.

20. Vanasse A, Scott S, Courteau J, Orzanco MG: Canadian family physicians' intentions to migrate: associated factors. Canadian Family Physician 2009, 55:396-397. e396.

21. Young R, Leese B, Sibbald B: Imbalances in the GP labour market in the UK: evidence from a postal survey and interviews with GP leavers. Work, Employment and Society 2001, 15:699-719.

22. Grosswald B: The effects of shift work on family satisfaction. Families in Society 2004, 85:413-423.

23. Madid S: Effects of night shift schedules nurses working in a priute hospital insouth Africa. Sweden: Luleal university of the technology 2003.

24. Chellappah M, Garnham L: Medical students' attitudes towards general practice and factors affecting career choice: a questionnaire study. London journal of primary care 2014, 6:117-123.

25. Verma P, Ford JA, Stuart A, Howe A, Everington S, Steel N: A systematic review of strategies to recruit and retain primary care doctors. BMC Health Services Research 2016, 16:126.

26. Lee DM, Nichols T: Physician recruitment and retention in rural and underserved areas. International journal of health care quality assurance 2014.

27. Marchand C, Peckham S: Addressing the crisis of GP recruitment and retention: a systematic review. British Journal of General Practice 2017, 67:e227-e237.

28. Russell DJ, Humphreys JS, McGrail MR, Cameron WI, Williams PJ: The value of survival analyses for evidence-based rural medical workforce planning. Human Resources for Health 2013, 11:65.

29. Puertas EB, Rivera TY: Factors that influence career choice in primary care among medical students starting social service in Honduras. Revista Panamericana de Salud Pública 2016, 40:309-317.

30. Costigliola V: Mobility of medical doctors in cross-border healthcare. EPMA Journa/2011, 2:333-339.

31. Chen LC: Striking the right balance: health workforce retention in remote and rural areas. SciELO Public Health; 2010.

32. Ünal E: How the government intervention affects the distribution of physicians in Turkey between 1965 and 2000. International Journal for Equity in Health 2015, 14:1. 
33. Toyabe S-i: Trend in geographic distribution of physicians in Japan. International journal for equity in health 2009, 8:5.

34. Sirikanokwilai N, Wibulpolprasert S, Pengpaiboon P: Modified population-to-physician ratio method to project future physician requirement in Thailand. Human Resources for Health Development Journal 1998, 3:55-67.

35. Sempowski IP: Effectiveness of financial incentives in exchange for rural and underserviced area return-of-service commitments: systematic review of the literature. Can J Rural Med 2004, 9:82-88.

36. Jabari A, Sharifirad G, Shokri A, Bahmanziari N, Kordi A: Overview of the performance of rural family physician in Iran. Health Inf Manage 2013, 9:1132-1145.

37. Albritton W, Bates J, Brazeau M, Busing N: Generalism versus subspecialization: changes necessary in medical education. Canadian Journal of Rural Medicine 2006, 11:126.

38. Barondess JA: The future of generalism. American College of Physicians; 1993.

39. ALIDOSTI M, Tavassoli E, KHADIVI R, SHARIFIRAD GR: A survey on knowledge and attitudes of rural population towards the family physician program in Shahr-ekord city. 2011.

40. Najimi A, Alidoosti M, Sharifirad G: Study of knowledge, attitude, and satisfaction toward the family physician program in rural regions of Isfahan, Iran. 2001.

41. Atefeh TA, Saeed H, Nadia O, Saeed M: Perception, awareness and expectations of people and physicians following the implementation of Family Physician (FP) Program : A case study of Shiraz. Journal of Medical Council of Iran 2015, 33:147-155.

\section{Figures}




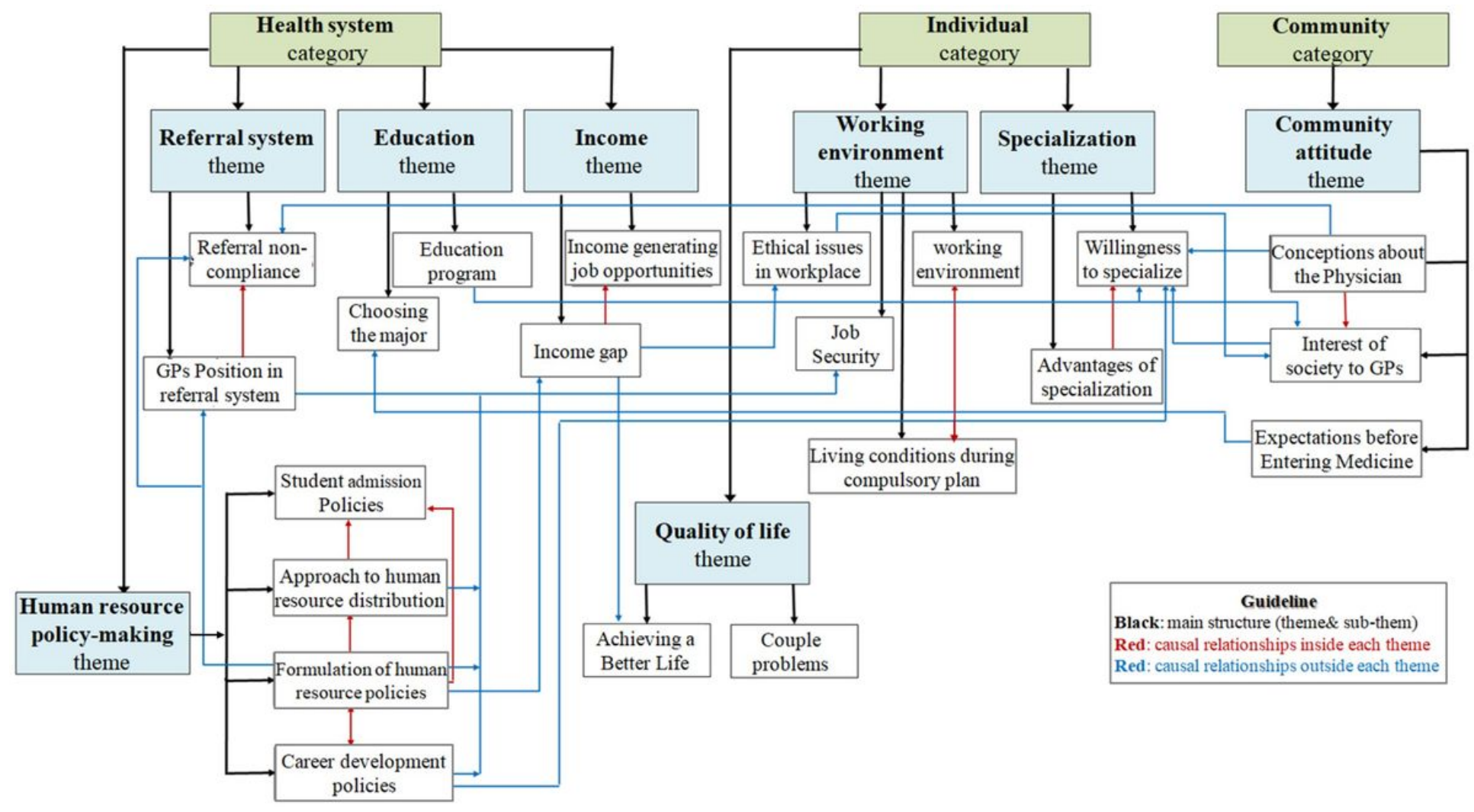

\section{Figure 1}

Conceptual model of causal relationships between factors (themes and sub-themes) influencing physicians' departure from General Practitioners field 